\title{
Facilitation of Innovative Pedagogical Activity of University Teachers
}

\author{
Petr Kubrushko \\ Russian Timiryazev State \\ Agrarian University \\ Pedagogy and Psychology of \\ Vocational Education \\ Department \\ Moscow, Russia \\ pkubrushko@mail.ru
}

\author{
Elena Kozlenkova \\ Russian Timiryazev State \\ Agrarian University \\ Pedagogy and Psychology of \\ Vocational Education \\ Department \\ Moscow, Russia \\ kozlenkova28@mail.ru
}

\author{
Oleg Mikhailenko \\ Russian Timiryazev State \\ Agrarian University \\ Pedagogy and Psychology of \\ Vocational Education \\ Department \\ Moscow, Russia \\ olegmih@yandex.ru
}

\author{
Liudmila Nazarova \\ Russian Timiryazev State \\ Agrarian University \\ Pedagogy and Psychology of \\ Vocational Education \\ Department \\ Moscow, Russia \\ nazarova@inbox.ru
}

\begin{abstract}
The authors outline innovative pedagogical activity of university teachers and consider a possibility of improving the mechanisms of its facilitation through the development of systematic scientific and methodological support for professional and personal self-development of teachers. An academic course of "Pedagogical Innovations" is put forward as a theoretical basis of this system. The technologies of facilitation of innovative pedagogical activity aimed at the activation of professional and personal self-development of teachers is exemplified by coaching practice in study activities.
\end{abstract}

Keywords-facilitation, innovative pedagogical activity, scientific and methodical support, professional-personal selfdevelopment, coaching in education.

\section{INTRODUCTION}

The today's world is characterized by rapid development of machinery and technologies, as well as a sharp increase in the volume of information and the speed of its transferring and processing. Under these circumstances, the system of professional education faces complex tasks, which require new fundamental approaches to tackle them. Professional activity of modern university teachers carried out in the information and educational environment calls for flexible productive thinking, creativity, highly developed innovative competence to work out and implement effective educational technologies that, in turn, contribute to the formation of innovative competencies in students.

The problem of developing readiness for innovation activity is of particular importance for the education of vocational training teachers, which provides the training of teachers for professional education system aimed at training highly qualified personnel for the innovative economy focused on the technologies of tomorrow. In this regard, the issues of improving the innovative pedagogical activity of university teachers [1] and, in particular, its facilitation are becoming even more urgent.

The task of forming the readiness of university teachers for innovative pedagogical activity is multifaceted. It is assigned primarily to the teachers themselves, who are expected to constantly improve their professional skills. A modern teacher runs the risk of becoming redundant in the new information society environment unless $\mathrm{s} / \mathrm{he}$ carries out continuous professional and personal self-development. However, not all teachers have sufficient skills of self-organization, collective problem-solving activity, reflexive techniques, and therefore need facilitation.

The task of an educational institution is to provide the required scientific, methodological, informational, psychological and other support to teachers and make favorable conditions for their professional self-implementation.

On the one hand, it is necessary to improve the contentand-methodological aspects of education for the innovative activity of future vocational training teachers in Bachelor's, Master's, and Post-graduate courses offered by vocational training teacher-training universities and faculties, since it is important to lay the foundation for their innovative competence at the stage of training. Moreover, this process can and should be extended to a stage of vocational guidance, when entrants only start choosing their future profession of a vocational training teacher.

On the other hand, it is necessary to develop a system of supplementary vocational education (advanced training, professional retraining), establishing a network of counseling and methodological support for professional activities of teachers.

\section{INNOVATIVE PEDAGOGICAL ACTIVITY OF THE TEACHER}

\section{A. Pedagogical Innovations as the Basis for Developing Readiness for Innovative Pedagogical Activity}

The development of innovative competence of teachers is of strait-through and implicit nature, encompassing many academic subject courses and various types of educational activities, each of which contributes to the development of readiness for innovations. Nevertheless, a special component the apical one - can be singled out in the content of vocational teacher training. This component is directly related to the theory and practice of innovative pedagogical activity and represented by a course of "Pedagogical Innovations". In 
Russian Timiryazev State Agrarian University, this course is offered within MSc and Post-graduate programs, as well as in the Center for Advanced Teacher Training, which is accredited by the International Society for Engineering Pedagogy IGIP.

The course of "Pedagogical Innovations" reveals the core and regular interrelations of innovative processes in education, studies the processes of creating pedagogical innovations (pedagogical neology), their evaluation and mastery by the pedagogical community (pedagogical axiology), and also practical applications (pedagogical praxeology). "Pedagogical Innovations" helps to answer the three main questions a teachers face in connection with the implementation of innovative pedagogical activity: "What?", "Why?" and "How?".

The object of research in "Pedagogical Innovations" is precisely the changes in education, but not education itself, and changes in their entirety - from identifying the causes of naturally occurring changes to the artificial design and implementation of pedagogical innovations, and the discovery of the laws of innovation processes [2].

Innovative processes in education are considered in three main aspects: social-and-economic, psychological-andpedagogical and organizational-and-managerial. Basing on this, the content of the "Pedagogical Innovations" course can vary depending on specific features of the professional activity of teachers taking professional development courses. MSc and post-graduate students also have an opportunity to choose certain topics of their interest to research specific innovative processes in education when carrying out projects.

The study of pedagogical innovations allows to solve a wide range of problems associated with:

- target and conceptual block of education;

- organizational structure of the education system, educational institutions, education management bodies, the system of advanced training, etc.;

- educational technologies;

- structure and content of education;

- educational programs, textbooks, electronic teaching aids;

- scientific and methodological support of the educational process;

- principles of education management and the quality of education;

- a system for monitoring, diagnosing, controlling and evaluating learning outcomes;

- economic aspects of education, state and interstate policy in education.

When studying pedagogical innovation in the Center for Advanced Training of Teachers, use is made of methods of collective creative activity aimed at organizing knowledge in the context of developing new experience and its personal implications. Of significant didactic value are such types of educational activities as research (stating the problem, putting forward and testing hypotheses, generating ideas, simulating experiments, etc.), discussion (identification and comparison of standpoints, positions, selection and presentation of arguments and so on), modeling (simulation and role-play activities, training sessions), reflexive (intellectual and emotional reflection). These types of educational activities mastered by teachers in the process of professional development are transferrable, i.e. can easily be adapted to the content of subjects they teach.

One of the main results of the study of pedagogical innovations by students is not only the psychological readiness for the implementation of innovative activities, but also the technological readiness, which assumes the mastery of innovative educational technologies [3]. The involvement of future teachers in real innovative activities (in the process of conducting master classes, conferences, open laboratories, production practices, performance of course projects and final qualification works basing on real production facilities, etc.) makes the study process possibly isomorphic to the future profession, and thus contributes to further employment of graduates and facilitates their professional adaptation.

\section{B. Innovative Competence of University Teachers}

An ability and willingness to carry out innovative activities is considered by many scientists as one of the leading competencies of a modern specialist in the innovation economy $[4 ; 5 ; 6]$.

In the framework of competences important for the organization and implementation of innovative activities, there are specific personality characteristics, among which there are professional, personal and specific traits aimed directly at the organization of innovation activity. Professional traits that determine the effectiveness of the organization of innovative activities include functional and creative components, personal traits consist of value orientations and the motivational component, specific traits comprise a high level of professionalism in the field of innovation management, creativity, enterprise, risk taking skills, purposefulness, ability to cooperation, etc. All these traits form the basis for the development of organizational and communicative competences of innovative activity participants based not so much on the epistemological aspects (development of new information about the organization of innovative activity in the study process), but rather on the psychological aspect (developing a personnel management style, improving the professional image, enhancing empathy and psychological insight, and so on).

Innovative competence, in fact, is metaprofessional and interdisciplinary by its nature. Its structure includes the cognitive component (knowledge), the emotive component (relations) and the praxiological component (activity). With respect to the cognitive component, the main difficulties for teachers are the lack of information, the skills of its searching and processing, the lack of knowledge about effective study technologies and strategies for the transfer of pedagogical innovations. With the emotional component, there are difficulties in determining the goals and methods of 
professional-and-personal self-development, value-based selfdetermination, and motivation for success in the profession. Difficulties encountered in the praxeological component are most often manifested in the form of a lack of professional experience in teachers and insufficient competences to solve professional problems.

\section{SPECIFIC FEATURES OF FACILITATION OF INNOVATIVE PEDAGOGICAL ACTIVITY}

\section{A. Facilitation in Study Process}

Unfortunately, in Russia there has not yet been sufficient distribution of special consulting services that provide qualified assistance in solving managerial and pedagogical problems. In fact, there is scientific and methodological support of vocational training teachers offered, first of all, by scientific advisers and consultants, advanced training and retraining institutions, scientific and methodological centers, educational management bodies, etc. there have been separate facts of training specialists for rendering professional consulting assistance to employees of educational organizations. Nevertheless, in recent years, more theoretical and practical attention has been paid to the problem of facilitating the activities of teachers.

In general, facilitation is understood as support, assistance, and contribution [7]. As a method of teaching, facilitation presupposes independent development of new knowledge by students in the process of group work in a "here and now" mode. This is a way of study interaction, in which all its participants can behave naturally, accept other people as they are and expect mutual acceptance, strive for mutual understanding and coordinate their positions through dialogue. Facilitation is also seen as a form of group communication aimed at achieving the goal of teamwork to generate new ideas or make decisions, while encouraging and guiding creative thinking of participants. In the study process, facilitation is applicable in any context, since pedagogical activity is always associated with interaction with other people - students, fellow teachers, heads of educational institutions, social partners, and others.

Michael Wilkinson formulates a structured facilitation methodology SMART Facilitation (Structured Meeting And Relating Techniques). SMART Facilitation is based on the eleven principles: Asking Questions; Preparing for Success; Getting the Session Started; Focusing the Group; Using the Pen; Information Gathering; Closing the Session; Managing Dysfunction; Building Consensus; Keeping the Energy High; Agenda Setting [8]. SMART Facilitation can be used to produce consistent, repeatable results.

\section{B. Technologies of facilitation of innovative pedagogical activity}

Psychological support of professional-and-personal selfdevelopment of teachers is carried out with the help of various innovative technologies. Coaching is one of such technologies, positively proved to be a tool of professional-and-personal selfdevelopment. In the broadest sense, it is considered as a science of change, philosophy and technology of integral personality development [9]. Coaching is associated with the dynamics of project thinking, development of self-analysis skills, professional motivation, and management of strategies for personal and professional growth.

Coaching is the art of creating a special development environment that helps a person achieve his/her goals in the professional and personal spheres. The conclusions, to which the client comes during the coaching session are his/her own discoveries, not imposed by the coach. Julie Starr calls such style of coaching a collaborative one. It implies the joint work of a coach and a coaching object (client) aimed at the introduction of changes [10]. A collaborative coach does not "fix" someone, neither tries to solve his/her problem, or "oversee" on him/her. On the contrary, a coach assumes that his/her client knows more about his/her situation than the coach himself/herself does. A coach believes in a person's ability to generate ideas that help solve his/her situation. A coach's task is to use tried-and-tested listening skills, asking questions and reasoning to build the most useful conversation for a client. In contrast to mentoring, the relationship between a coach and a client is of a partnership nature.

Coaching acts as a means to increase awareness, responsible personal choice of life and professional path, accelerate professional and managerial achievements.

The main tool of the coach is open questions that encourage people to independently investigate their request and often lead to insights. In coaching, various interactive techniques are used that promote the disclosure of hiddenrespources, increase motivation, and the result is an independent acceptance by the client of an important decision, the development of a strategy of behavior. Widely distributed are also the following tools: the GROW model, the methods of active listening, visualization, scaling, operating with values, beliefs, motivations, and fears; Eisenhower's matrix, Cartesian coordinates, logical level system, "life balance wheel", "minimum - 100\% - maximum" approach and other methods.

Destruction of mental stereotypes and formation of new habits resulting from the interaction between a coach and a client often causes psychological resistance to a person, and is therefore important for a client to understand that development begins outside the comfort zone and that s/he has all the necessary resources to achieve his/her goals.

\section{CONCLUSION}

Thus, the facilitation of innovative pedagogical activity is a kind of scientific and methodological support of the professional activity of teachers as a system of interrelated functions, actions, procedures, methods, techniques and activities that are provided in a variety of forms and technologies aimed at offering qualified assistance to a teacher throughout his/her professional career. It is important to note the need to facilitate rather than directly foster the professional and personal self-development of a teacher, offering him/her the right to make independent decisions in the selection and design of strategies and methods of professional activity.

To optimize the facilitation process of innovative pedagogical activity carried out by teachers, it is necessary to 
establish specialized centers for pedagogical consulting that provide the following opportunities:

- optimization of innovation in the interaction of universities with other links in the system of continued education;

- professional development of teachers within individual programs;

- training of academic staff in joint search for effective models and innovative technologies of pedagogical activity;

- organization of psychological counseling in stressful situations and pedagogical coaching aimed at the actualization of internal forces and reserve capacity of a teacher to enable him/her to solve problems of professional and personal self-development, etc.

\section{REFERENCES}

[1] P. F. Kubrushko, and L. I. Nazarova, "Professional Development of Technical University Lecturers in Field of Innovation Teaching", in 2013 International Conference on Interactive Collaborative Learning, ICL 2013, pp. 467-469.
[2] J. Branch, S. Hayes, A. Horsted, and C. Nygaard, "New Innovations in Teaching and Learning in Higher Education", The Learning in Higher Education Series, 2018, 484 p.

[3] F. Marton, D. Hounsell, and N. J. Entwistle, "Approaches to learning", in The experience of learning: Implications for teaching and studying in higher education, 3rd ed., vol. 1, Edinburgh: University of Edinburgh, Center for Teaching, Learning, and Assessment, 2004, pp. 151-159.

[4] J. Bordogna, E. Fromm, and E. W. Ernst, "Innovation Through Integration", in Journal of Engineering Education, vol. 82, № 1, pp. 3-8, January 1993.

[5] W. E. Blank, "Handbook for Developing Competency-Based Training Programs", New-Jersey: Prentice Hall, 1982, 378 p.

[6] V. G. Lizunkov, O. T. Ergunova, and E. Y. Malushko, "Forming system of strategic innovation management at high-tech engineering enterprises" in IOP Conference Series: Materials Science and Engineering, vol. 177, № 1, 2017, Article number 012046, pp. 1-7.

[7] D. Hunter, A. Bailey, and B. Taylor, "The Art of Facilitation", Tandem Press, 2002, $256 \mathrm{p}$.

[8] M. Wilkinson, "The Secrets of Facilitation. The SMART Guide to Getting Results with Groups", John Wiley \& Sons Limited, 2012, 435 p.

[9] J. Starr, "The coaching manual. The definition guide to the process, principles and skills of personal coaching", 4th ed., Pearson Education Limited, 2016, $368 \mathrm{p}$.

[10] F. M. Stone, "Coaching, counselling and mentoring", McGraw-Hill, $2007,240 \mathrm{p}$. 